\title{
Observação da Saúde em seus Múltiplos Aspectos
}

\author{
Health Observation in its Multiple Aspects
}

Observación de la Salud en sus Múltiples Aspectos

Divanise Suruagy Correia $^{1}$

Temos visto crescer nos últimos tempos no Brasil, e consequentemente no estado de Alagoas, as enfermidades crônicas e os agravos como fatores de adoecimento da população. A saúde definida como interação entre fatores biológicos, sociais, emocionais e espirituais, traz em seu conceito a diversidades desses fatores como determinantes do desequilíbrio e consequentemente adoecimento. Por muito tempo este desequilíbrio era visto apenas pelo lado biológico e físico, sendo separado mente e corpo, espírito e ser. Atualmente, vem ocorrendo pequenas modificações nos paradigmas da Ciência, e novas pesquisas mostram que o equilíbrio entre a mente e o corpo, também sofre a influência do espiritual.
Assim, o ser humano passa a ser estudado holisticamente.

Trazemos neste número artigos relacionados a aspectos biológicos, mentais e sociais, além da formação e gestão. A obesidade, a violência obstétrica e o Transtorno do Espectro Autista (TEA) aparecem estre os temas aqui abordados.

O TEA

apresenta comprometimento em três áreas do desenvolvimento: nas habilidades sociais, nas habilidades comunicativas e nos comportamentos restritos, repetitivos e estereotipados. No mundo, a prevalência do TEA pode atingir $1,47 \%$ da população mundial. No Brasil, observamos avanços quanto a identificação precoce e ao diagnóstico

${ }^{1}$ Professora associada da Faculdade de Medicina da Universidade Federal de Alagoas. Autora correspondente: Campus A. C. Simões. Av. Lourival Melo Mota, s/n. Tabuleiro dos Martins. 57072-900. Maceió, Al, Brasil. E-mail: divanisesuruagy@gmail.com Recebido: Ago/2017 - Aceito: Ago/2017. 
do TEA, o que mostra a relevância do artigo ora publicado.

A depressão é resultante de alterações na função e efeito de neurotransmissores e da forma como eles interagem com os diversos neurocircuitos que compõem o cérebro. Ela surge após a combinação de vários fatores, como os biológicos, os psicológicos, os sociais, tão presentes no cotidiano das pessoas, aparecendo frequentemente como problema de saúde pública. Na população idosa, sua prevalência pode chegar aos $15 \%$ entre idosos da população geral, aumentado para $60 \%$ entre os institucionalizados. A Organização Mundial da Saúde estima que a depressão é a principal causa de deficiência mental em todo o mundo. Assim, o artigo sobre a depressão geriátrica em uma comunidade de Maceió mostra-se relevante para o estudo desta patologia.

$\mathrm{O}$ aumento de peso vem ocorrendo na população mundial e a obesidade mórbida surge como patologia que acomete todas as faixas etárias. Nos adultos jovens demonstrase a associação entre o aumento da gordura abdominal e fatores de risco cardiovasculares, resistência à insulina e outros distúrbios metabólicos que podem levar a morte. São diversos os tratamentos para a obesidade, até se chegar a realização da cirurgia bariátrica que é discutida no artigo Impacto da cirurgia bariátrica na qualidade de vida.

As escolas de medicina, no Brasil, vêm introduzindo o médico cada vez mais cedo nos serviços de atenção básica obedecendo as Diretrizes Curriculares Nacionais, todavia a formação hospitalar continua sendo importante ao se visualizar a atuação médica nos diversos níveis de atenção à saúde. As questões teóricas e práticas no campo da saúde relacionam-se com o avanço da ciência médica e a clínica da medicina continua imprescindível para a atuação e formação médica. Desta forma, o aprimoramento das técnicas de diagnóstico e de tratamento levam a maiores chances de acerto e de identificação de um órgão lesado. Neste sentido, a preceptoria é de suma importância o que se revela no artigo "Visão de preceptores sobre o processo de ensino - aprendizagem de residentes de clínica médica".

\section{A Política Nacional de} Humanização (PNH) é uma política nacional que visa qualificar a atenção e gestão na rede do Sistema Único de Saúde $\quad$ (SUS), $\quad$ abrangendo trabalhadores, usuários e gestores. Lançada em 2003, a PNH busca pôr em prática os princípios do SUS no dia a dia dos serviços de saúde. Estimula a 
comunicação entre todos na busca de processos coletivos para o enfrentamento de relações de poder, trabalho e afeto que muitas vezes causam atitudes desumanizadoras que inibem a autonomia e responsabilidade dos profissionais de saúde e dos usuários no próprio cuidado. Aposta na inclusão de todos na produção e gestão do cuidado e dos processos de trabalho e na comunicação entre esses três atores do SUS. A avaliação discutida no artigo "Política Nacional de Humanização: Implementação do Grupo de Trabalho de Humanização em uma Unidade de Saúde de Maceió", traz à tona este tema despertando reflexão e atualização da situação local.

A humanização também é necessária na dinâmica do Trânsito. Mais uma vez trazemos nesta revista algo relacionado a este tema com o artigo intitulado: "Avaliação psicológica em condutores de automóveis: Uma revisão sistemática, que aborda o processo avaliativo, atribuído ao psicólogo sendo fonte de informações de caráter explicativo sobre os fenômenos psicológicos".

Outro aspecto da gestão na saúde é apresentado no projeto de intervenção intitulado, “A Padronização do Fluxo de Atendimento do Centro Especializado em Reabilitação - CER
III", servindo de modelo para novos projetos de Intervenção na saúde.

Constantemente, consideramos nossos riscos e buscamos nos proteger, procurando afastar situações que estão associadas à ocorrência de eventos indesejáveis. Risco é uma noção moderna que está relacionada à procura de rumos originais, nas relações com acontecimentos que podem ocorrer no futuro. Apesar de ser antigo o ato de busca de prevenção, Mary Spink afirma que este conceito, na modernidade, surge como (re)significação das situações de perigo, tentativa de 'domesticar o futuro', prendendo-o em uma rede explicativa de fatos conhecidos. O artigo "Implicações da individualização, risco e reflexividade para saúde e doença na contemporaneidade", nos faz pensar sobre tudo isto.

Finalmente trazemos a resenha sobre "Segurança do Paciente".

E em tempos de final de ano, desejamos a todos um Feliz 2018, agradecendo a todos colaboradores de nossa revista. 